\title{
Satellite Estimation and Ground Based Measurements of Solar UV Index in Kathmandu
}

\author{
Niranjan Prasad Sharma \\ Department of Engineering Science and Humanities, Institute of Engineering, Central Campus, Pulchowk, \\ Tribhuvan University, Nepal \\ Corresponding email: sharmaniranjanprasad@ hotmail.com
}

\begin{abstract}
The study is based on the satellite estimation and ground measurements of solar UV index in Kathmandu for the year 2009. Kathmandu (27.720N, 85.320E) is located at an elevation of $1350 \mathrm{~m}$ from the sea level. The ground based measurement and satellite estimation was performed by NILU-UV irradiance meter and EOS Aura OMI spacecraft. The NILU-UV irradiance meter measures UV radiation in different spectral range. The Ozone Monitoring Instrument (OMI) is a spectrometer designed to monitor solar radiation in spectral range of (270-500) $\mathrm{nm}$. This study shows that satellite overestimates the ground based (GB) UV Index (UVI) before monsoon by $103.6 \%$ whereas during the monsoon period overestimation comes down to $70.8 \%$. The correlation coefficient (r) between ozone column from satellite and ground based measurement before monsoon and after monsoon is also studied. It is observed that the correlation between satellite estimated ozone column and ground based ozone column before and after monsoon is 0.83 . The study showed that the estimation of OMI before monsoon is high than after monsoon.
\end{abstract}

Keywords: OMI, Aura, Ozone, Ultraviolet, UV Index

\section{Introduction}

The amount of solar ultraviolet (UV) radiation $(200-400 \mathrm{~nm}$ ) reaching the earth's surface is affected mainly by atmospheric ozone absorption, cloudiness and aerosols. Changes in UV radiation at surface may strongly affect the human health and the terrestrial and aquatic ecosystems [13].

Surface UV radiation estimates have been provided from the Ozone Monitoring Instrument (OMI), flying on the NASA EOS Aura spacecraft since 15 July 2004. OMI is a spectrometer designed to monitor ozone and other atmospheric species [10]. Two algorithms, OMI-TOMS and OMI-DOAS (Differential Optical Absorption Spectroscopy), are used to produce OMI daily total ozone datasets. OMI UV products are local solar noon irradiance at 305,310, 324, and 380 $\mathrm{nm}$, as well as EDRs and Erythemal Daily Doses (EDDs). OMI continues the Total Ozone Monitoring System (TOMS) record of total ozone, aerosol, and UV measurements. Satellite ozone and UV data derived from TOMS were exhaustively validated by means of ground-based ozone and UV data $[2,5,1,8]$. Brogniez et al. (2005) found a reasonably good agreement between satellite ozone data and ground- based measurements retrieved in six European sites: generally the ground-based ozone seems to be slightly than TOMS ozone (less than 3\%). Regarding UV data, Fioletov et al. (2002) found that erythemal UV estimates from TOMS demonstrate better agreement with ground-based measurements in case of low level of pollution. Arola et al. (2005) compared TOMS overpass retrievals against Brewer measurements at Ispra (Italy) and Thessaloniki (Greece), obtaining large positive biases in both cases (on average about 19\% for Ispra and 30\% for Thessaloniki). They found that these discrepancies can be mainly 
explained by the aerosol effect. Kazantzidis et al. (2006) confirmed that TOMS UV data overestimate ground-based measurements by almost $20 \%$ under high aerosol load.

Kathmandu is the capital and largest metropolitan city of Nepal. The city is the urban core of Kathmandu valley which contains two sister cities namely Patan $5 \mathrm{~km}$ to its southeast and Bhaktapur $14 \mathrm{~km}$ to its east and is a touristic destination centre. Satellite estimation and ground based measurements of UV radiation has not been performed in Kathmandu. Being located at high altitude UV Index and UV dose in Kathmandu is expected to be higher. UV Index is an indicator that helps to measure the effect of solar ultraviolet radiation on human skin. It is an important indicator and is useful to raise public awareness for skin damage. The higher the Index, the greater the risk of skin damage due to UV radiation. UV index differs from place to place and depends upon different factors. Ozone, aerosols, clouds, solar elevation, altitude and albedo are the factors that affect solar UV radiation reaching the earth's surface. Thus the ground based measurement of UV radiation with satellite estimation at Kathmandu is an important part of the study. The main aim of this study is to present the ground based solar UV index with OMI estimation in Kathmandu. The paper emphasized to compare the UVI at Kathmandu during monsoon and before monsoon. The correlation between ground based UV Index (UVI) with OMI estimated UVI is also analyzed. The paper also focused to compare ground based total ozone with OMI.

Section 1 represents the introductory part of UV radiation. Methodology is given in section 2. Results and discussion of the UV measurement is presented in section 3. Conclusions of the measurement are included in section 4 .

\section{Instrumentation and Methodology}

\subsection{Ground based observation}

The instrument used to measure solar UV irradiance at Kathmandu $\left(27.72^{\circ} \mathrm{N}, 85.32^{\circ} \mathrm{E}\right)$ is NILUUV irradiance meter. The various types of instruments all have their pros and cons depending on the manpower available for their operation, the location and accessibility of the measurement site, and the accuracy, stability, and the quality requirements of the measurements. The need for an accurate and reliable instrument that could operate independently in harsh environments with in-board storage of data and the possibility for the remote down-load of data through public telephone lines motivated development of the Norwegian Institute for Air Research UV radiometer (NILU-UV). The NILU-UV instrument is a multichannel, moderate-bandwidth filter instrument. It is a six-channel moderate-bandwidth filter instrument. Five of the channels are in the UV with centre wavelengths at $305,312,320,340$, and $380 \mathrm{~nm}$ and a bandwidth of $10 \mathrm{~nm}$ at FWHM. The sixth channel measures the so-called photo synthetically active radiation. It covers wavelengths between 400 and $700 \mathrm{~nm}$ with a bandwidth of $300 \mathrm{~nm}$ at FWHM. The front optics consists of a flat Teflon diffuser followed by custom-made interference filters from Barr Associates, Inc., Westford, Mass. To minimize stray-light problems the five UV channels in addition have UG-11 and read leak filters. For the same reason the 305, 312, and 320nm channels are equipped with individual specified short-pass filters. For all channels the radiation is recorded by $\mathrm{S} 1226-8 \mathrm{BQ}$ silicium detectors from Hamamatsu. The instrument is the temperature stabilized at $50^{\circ} \mathrm{C}$. It records data in a built in data logger at a 1-min time resolution. The data logger has the capacity to store 3 weeks of 1 min averages. By interfacing the instrument to a computer using a RS-232 port, data with 1-s tine resolution may b recorded. The 
total weight of the instrument ready for operation is $3 \mathrm{~kg}$ the instrument is weatherproof and designed to operate in harsh environments (Hoiskar et al., 2003).

\subsection{Satellite observation}

OMI, the ozone monitoring instrument flying on Aura, is the latest of a series of ozone mapping instruments. In terms of the long-term ozone data record OMI can be considered an advanced version of the total ozone mapping spectrometer (TOMS). A series of TOM'S instruments flew on Nimbus 7 (November 1978 to May 1993), Meteor 3 (August 1991 to December 1994) and earth Probe (August 1996 to December 2005). OMI continues this time series of global total column ozone measurements.

OMI is the Dutch-Finnish contribution to EOS-Aura OMI is a nadir viewing, wide swath, ultraviolet-visible (UV-VIS) imaging spectrometer that provides daily global measurements of the solar radiation backscattered by the Earth's atmosphere and surface, along with measurements of the solar irradiance. Full instrument details of OMI have been given elsewhere [10], but details relevant to ozone retrieval are summarized here. Unlike the heritage TOMS instruments which measure ozone at six discrete wavelengths from $306 \mathrm{~nm}$ to $380 \mathrm{~nm}$ [11], OMI measures the complete spectrum from $270 \mathrm{~nm}$ to $500 \mathrm{~nm}$ at an average spectral resolution of 0.5 $\mathrm{nm}$. OMI combines the advantages of GOME and SCIAMACHY [3], measurement of the complete spectrum in the ultraviolet/visible wavelength range, with the advantages of TOMS, complete spatial coverage. The UV channel consists of two sub channels: the UV-1, ranging from 270 to $310 \mathrm{~nm}$, and the UV-2, ranging from 310 to $365 \mathrm{~nm}$. The total ozone retrieval is based on measurements from the UV-2 detector. The VIS-channel covers the range from 365 to $500 \mathrm{~nm}$.

The nadir pointing telescope of OMI has a very large field of view of $114^{\circ}$ perpendicular to the flight direction of the satellite. This gives OMI a swath width of $2600 \mathrm{Km}$, consisting of 60 individual pixels along the swath. The instrument achieves complete daily global coverage of the sunlit earth. The state of the art CCD detectors render a very high spatial resolution of $13 \mathrm{~km} \times$ $24 \mathrm{~km}$ at nadir. The small ground pixel size enables OMI to look 'in between' the clouds, giving better reach into the troposphere for retrieving tropospheric composition information than any other UV-VIS backscatter instrument flown to date.

\section{Results and Discussion}

This study analyzes the variation of the noon time ground based measurement and the satellite estimated solar UV index for the year 2009. Alongside, the study also emphasizes on correlating the ground based daily total ozone with the satellite estimated ozone before and during monsoon. Figure 1 shows the daily variation between the noon time ground based and the satellite estimated solar UV index. This figure clearly shows that for a given day the satellite data are always estimated greater than the corresponding ground based data. 




Figure 1: Daily variation of ground based and satellite estimated UV Index

In fact the satellite overestimated by around $71.9 \%$ in comparison to the ground UVI. The overestimation of OMI with GB UV index could be mainly due to the variability between solar noon times and overpass times. Looking at a given time and location the SZA is the dominant factor that determines the spectral detail as well as absolute solar UV irradiance. As a consequence the UV spectrum depends on location, on the time of the day and on the day within a year [12].

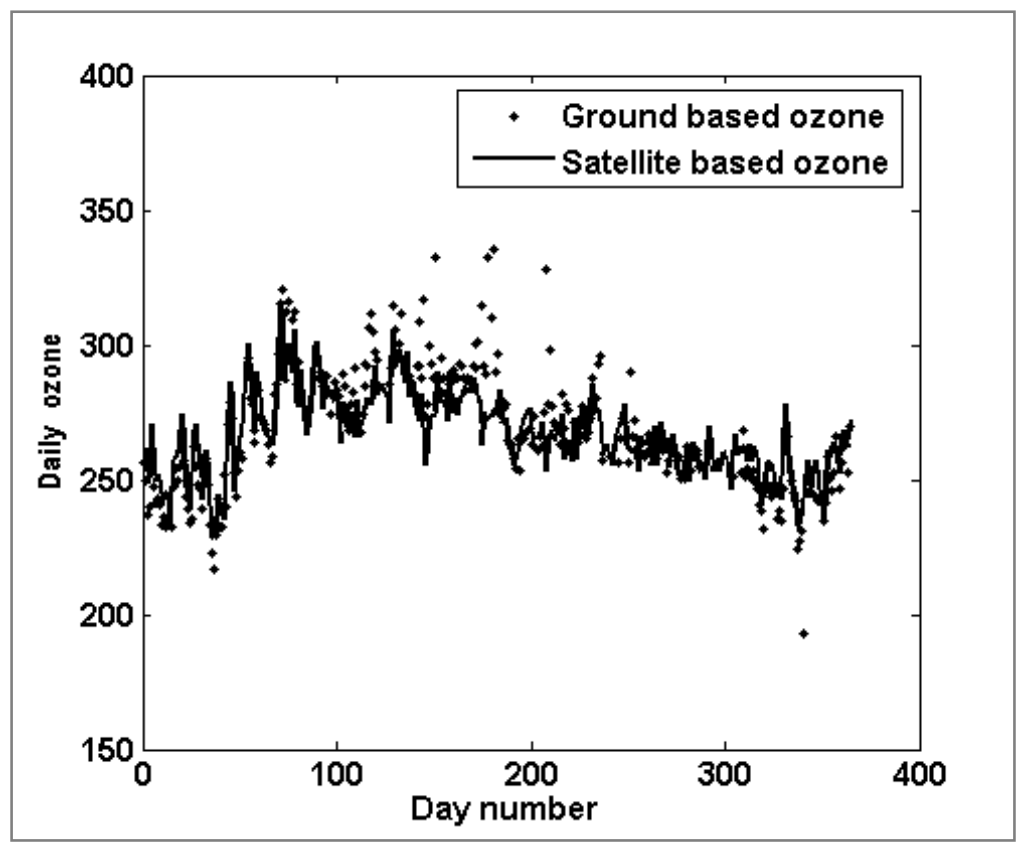

Figure 2: Daily variation of ground based and satellite estimated ozone 
It is observed from the figure above that, the GB daily mean total ozone column is $18.0 \%$ higher than the corresponding OMI value. The reason behind this ground based overestimation might be due to clouds present in the OMI grid. The mean difference between daily total ozone column amounts derived from NILU-UV measurements and from Earth Probe TOMS data was $-1.4 \%$ $\pm 3.2 \%$ [4].

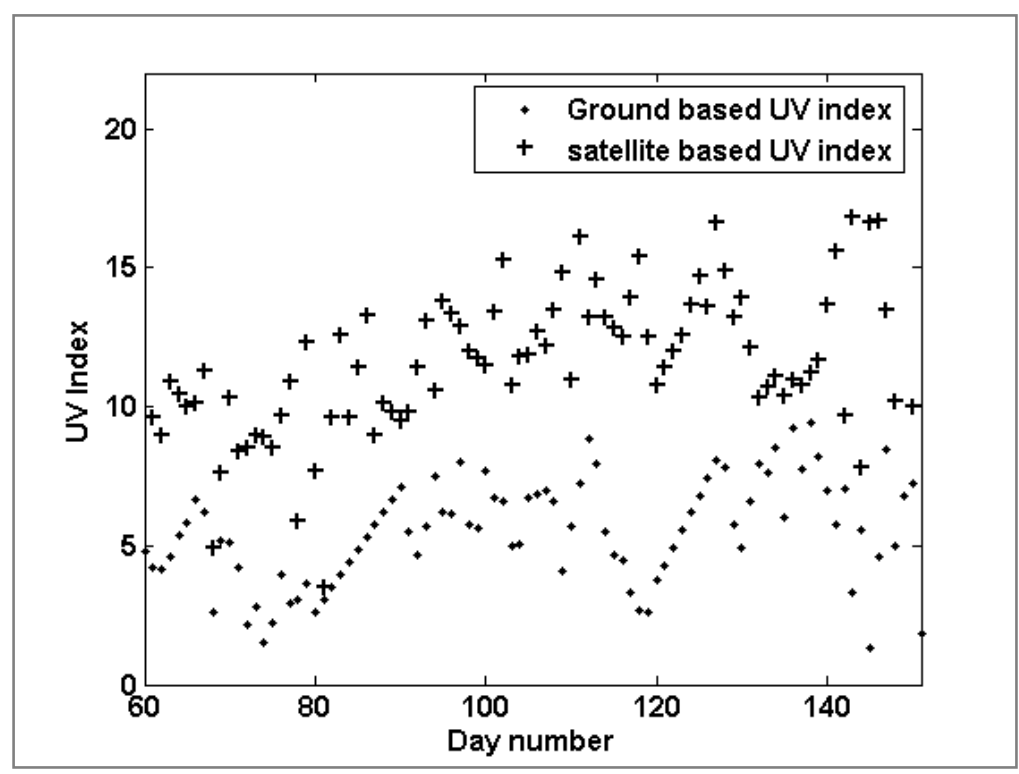

Figure 3: Scatter plot of GB and OMI estimation of solar UV Index before monsoon

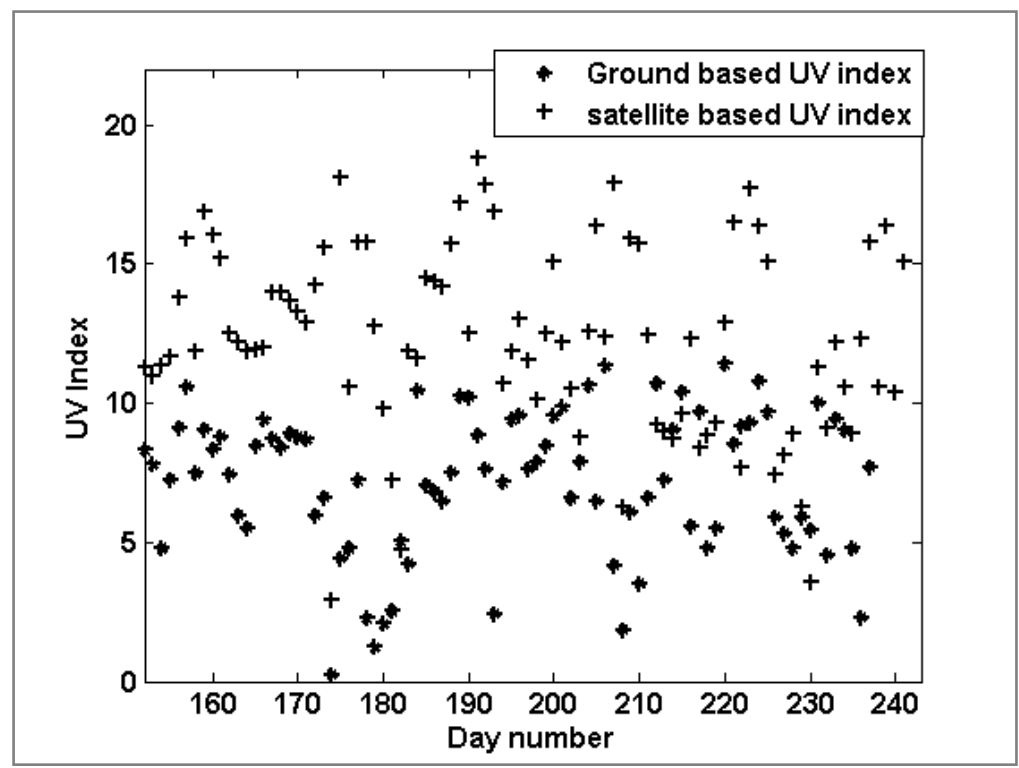

Figure 4: Scatter plot of ground based and satellite estimated UV Index during monsoon

The analysis above (Figure 3 and 4 ) shows that the satellite overestimates the ground based UVI by about $103.6 \%$ before monsoon whereas the GB UVI falls down to $70.8 \%$ during monsoon. The fluctuation in UV data before monsoon is mainly due to the combined effect of clouds and 
aerosols. During monsoon the aerosols and pollutants are washed out and cloud plays a dominant role in attenuating solar UV radiation reaching the earth surface. The OMI overestimation of ground-based UV measurement may be partly explained with the fact that satellite instrument do not prove well the lower atmospheric layers of urban sites where aerosols play an important role $[9,8]$. The correlation coefficient (r) with total number of data points $(\mathrm{n})$ between ground based UVI and OMI UVI before monsoon and during monsoon period are shown in figure 5 and 6.

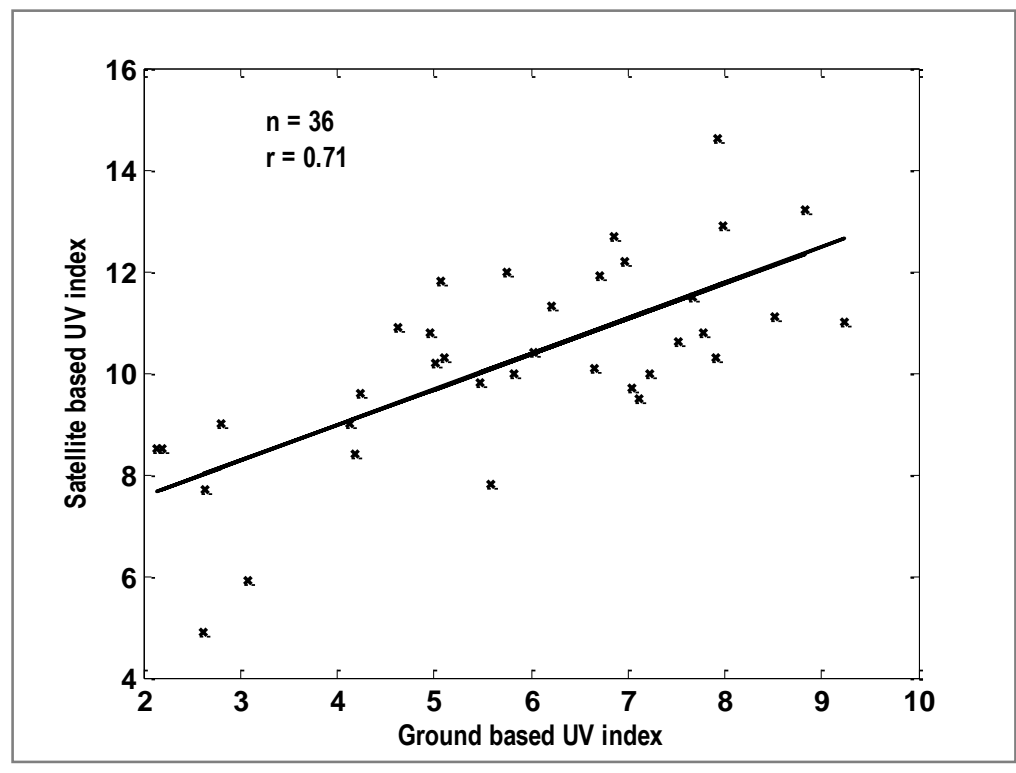

Figure 5: Scatter plots of GB and OMI UVI in March, April and May (The solid black line represents the linear fit)

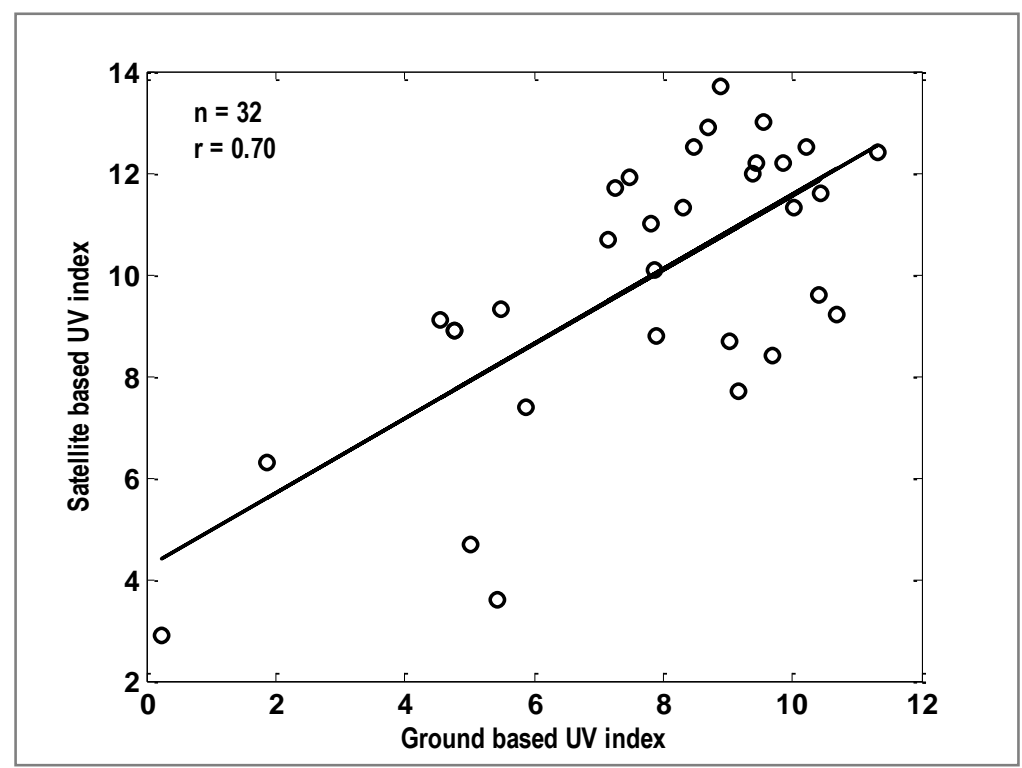

Figure 6: Scatter plots of GB and OMI, UV Index in June, July and August (The solid black line represents the linear fit) 
The analysis showed that correlation coefficient (r) between ground based and OMI UVI were found to be 0.71 before monsoon while during monsoon it was 0.70 . In monsoon more fluctuation in UV data are mainly due to the presence of cloud in the atmosphere. Figure 7 and 8 represents the correlation between ground based total ozone and OMI estimated total ozone.

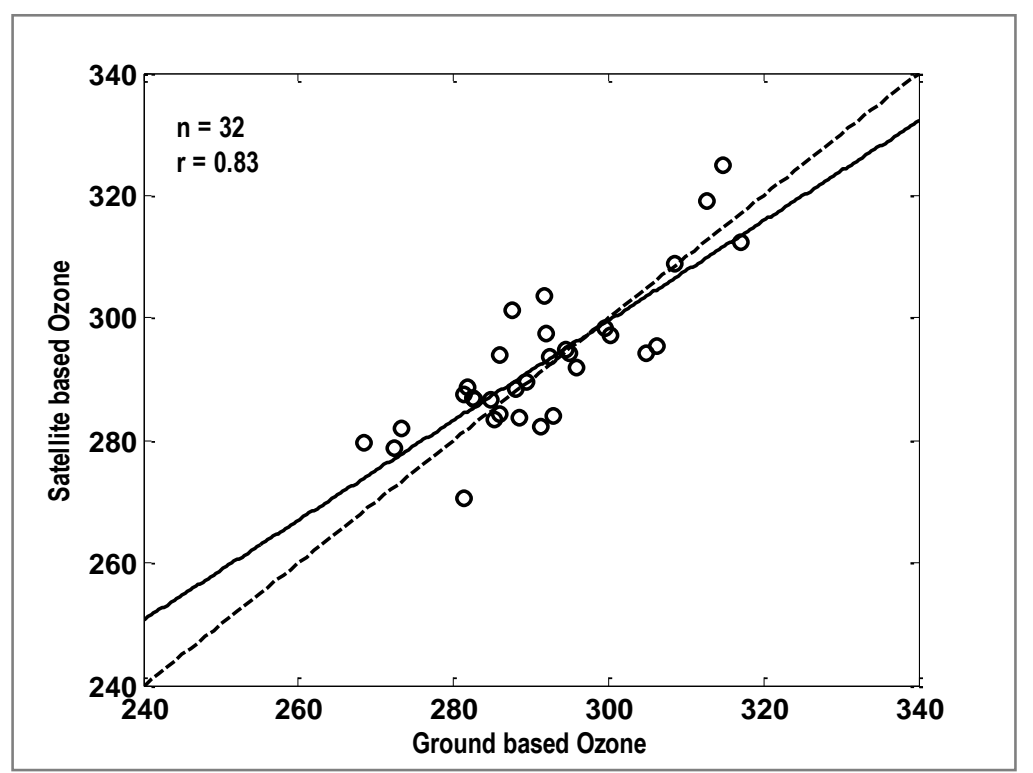

Figure 7: Correlations between GB and OMI UVI in March, April and May

(The solid black line represents the linear fit and the dashed line is ideal regression of unit slope)

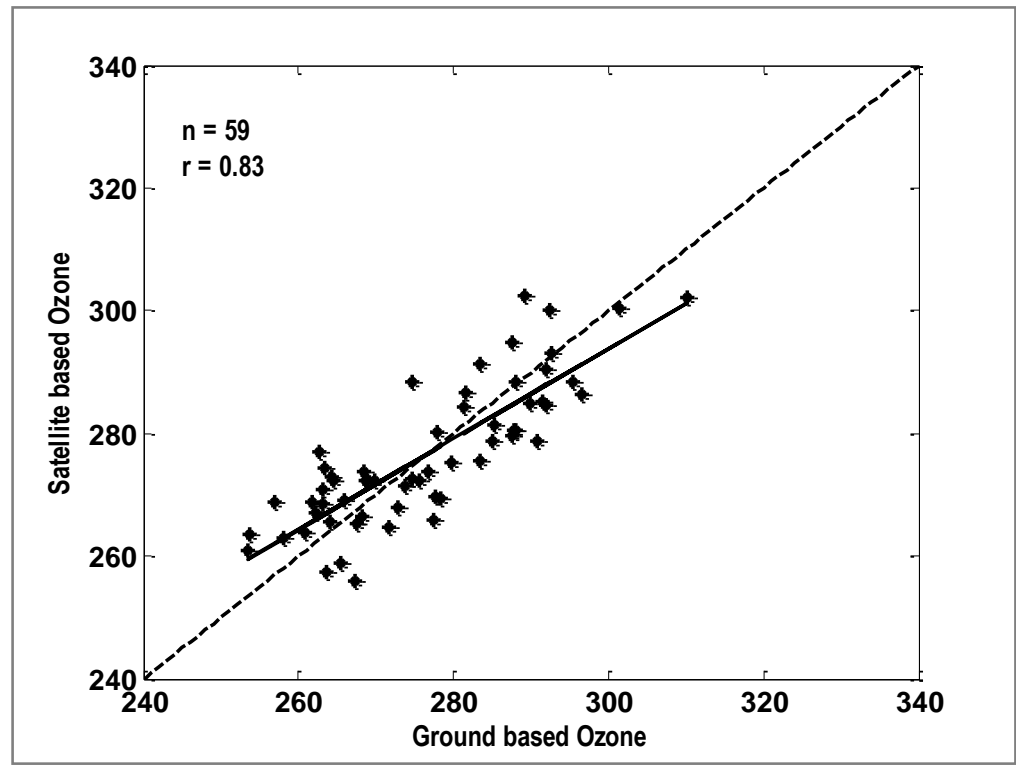

Figure 8: Correlations between GB and OMI ozone in June, July and August

(The solid black line represents the linear fit and the dashed line is ideal regression of unit slope)

The study showed that the correlation between ground based ozone and OMI estimated ozone is found to be 0.83 before and during monsoon. The correlation coefficient (r) in Rome station 
$\left(41.9^{\circ} \mathrm{N}, 12.5^{\circ} \mathrm{E}\right)$ is 0.97 under all sky conditions [7]. Thus, there is good agreement in ground based daily total ozone data and OMI daily total ozone data in Kathmandu for all sky conditions.

\section{Conclusions}

The satellite estimated and ground based measurements of solar UVI in Kathmandu, Nepal using Ozone Monitoring Instrument and high quality ground-based measurements were analyzed and reported. The comparison between GB noon time UVI and OMI noon time UVI showed that, on an average OMI exceeds the ground based measurements by more than $103.6 \%$ before monsoon and $70.8 \%$ during monsoon. On further analysis it was found that the overestimation of UVI before monsoon was greater than that after monsoon. The main cause of this overestimation is that the ground based instrument measures the UV irradiance at a single point while OMI measures the UV irradiance over a large area. Apart from this the dusty events of Kathmandu might also be the cause of overestimation. The analysis also showed that the correlation coefficient(r) between ground based ozone and OMI based ozone before and during monsoon were 0.83 for all sky condition.

\section{Acknowledgements}

The authors are grateful to Solar Radiation and Aerosol Project in the Himalaya region (SAHR) for providing data and other support. The authors are also grateful to Aura Validation Center (NASA) for providing OMI data.

\section{References}

[1] Arola, A., Kazadzis, S., Krotov, N., Bais, A., Grobner, J., and Herman, J. R. (2005). Assessment of TOMS UV bias due to absorbing aerosols, Journal of Geophysical Research, 110, D23211, doi: 10.1029/2005JD005913.

[2] Brogniez, C., Houet, M., Siani, A. M., Weilhs, P., Allaart, M., Lenoble, J., Cabot, T., de la Casiniere, A., and kyro, E, (2005). Ozone column retrieval from solar UV measurements at ground level: Effects of Clouds and results from six European sites, Journal of Geophysical Research, 110, D24202, doi:10.1029/2005JD005992.

[3] Burrows, J. P., Weber, M., Buchwitz, M., Rozanov, V., Weibenmayer, L., Richter, A., Debeek, R., Hoogen, R., Bramstedt, K., Eichmann, K. U., and Eisinger, M. (1999). The Global Monitoring Experiment (GOME): Mission concept and first scientific results, Journal of Atmospheric Sciences, 56, 151-175, doi:10.1175/1520-0469.

[4] Dahlback, A., Gelsor, N., Stamnes, J. J., and Gjessing, Y. (2007). UV measurements in the 3000-5000m altitude region in Tibet, Journal of Geophysical Research, 112, D09308, doi: 10.1029/2006JD007700.

[5] Fioletov, V. E., Kerr, J. B., Wardle, D. I., Krotkov, N., and Herman, J.R. (2002). Comparision of Brewer ultraviolet irradiance measurements with total ozone mapping spectrometer satellite retrievals, Optical Enggineering, 41, 3051-3061.

[6] Hoiskar, B.A.K., Haugen, R., Danielsen, T., Kylling, A., Edvardsen, K., Dahlback, A., Johnsen, B., Blumthaler, M., Schreder, J. (2003). Multichannel moderate-bandwidth filter instrument for measurement of the ozone-solumn amount, cloud transmittance, and ultraviolet dose rates, Applied optics, 42(18).

[7] Ialongo, I., Casale, G. R., Siani, A. M. (2008). Comparision of total ozone and eryhtemal UV data from OMI with ground-based measurements at Rome station, Atmospheric Chemistry Physics, 8, 3283-3289. 
[8] Kazantzidis, A., Bais, A. F., Grobner, J., Herman, J. R., Kazadizis, S., Krotkov, N., Kyro, E., den Oiter, P. N., Garane, K., Gorts, P., Lakkala, K., Meleti, C., Slaper, H., Tax, R. B., Turunen, T, and Zerefos, C. S. (2006). Comparisson of satellite-derived UV irradiances with ground-based measurements at four European stations, Journal of Geophysical Research, 111, D13207, doi: 10.1029/2005JD006672.

[9] Krotkov, N. A., Bhartia, P. K., Herman, J. R., Fioletov, V., and Kerr, J. (1998). Satellite estimation of spectral surface UV irrandiance in the presence of tropospheric aerosols: 1. Cloud-free case, Journal of Geophysical Research, 103(D8), 8779-8793.

[10] Levelt, P. F., van den Oord, G. H. J., Dobber, M. R., Malkki, A., Visser, H., de Vries, J., Stammes, P., Lundell, J., and Saari, H. (2006). The Ozone Monitoring Instrument, IEEE Transactions on Geoscience and Remote Sensing, 44, 5, 1093-1101.

[11] McPeters, R. D. (1998). Earth Probe Total Ozone Mapping Spectrometer (TOMS), Data Products User's Guide, NASA/TP-1998-206895, NASA, Washington, D. C.

[12] Secmeyer, G., Pisssulla, D., Giandorf, M., Henriques, D., Johnsen, B., Webb, A., Siani, A.M., Bais, A., Kjeidstad, B., Brogniez, C., Lenobie, J., Gardiner, B., Kirsh, P., Koskela, T., Kaurola, J., Uhlmann, B., Siaper, H., Casiniere, A.D.L., Simic, S., and Carvalho, F. (2008). Variability of UV Irradiance in Europe, Photochemistry and Photobiology, 84, 1, 172-179.

[13] UNEP (2007). Environmental effects of ozone depletion and its interactions with climate change assessment, 2006, Photochemistry Photobiological Sciences, 6, 3, 201-332. 